\title{
ARTICLE
}

\section{The mucosal surfaces of both eyes are immunologically linked by a neurogenic inflammatory reflex involving TRPV1 and substance P}

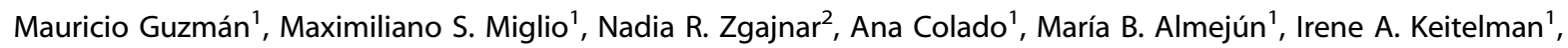
Florencia Sabbione ${ }^{1}$, Federico Fuentes ${ }^{1}$, Analía S. Trevani ${ }^{1,3}$, Mirta N. Giordano ${ }^{1,3}$ and Jeremías G. Galletti ${ }^{1}$

Immunological interdependence between the two eyes has been reported for the cornea and the retina but not for the ocular mucosal surface. Intriguingly, patients frequently report ocular surface-related symptoms in the other eye after unilateral ocular surgery. Here we show how unilateral eye injuries in mice affect the mucosal immune response of the opposite ocular surface. We report that, despite the lack of lymphatic cross-drainage, a neurogenic inflammatory reflex in the contralateral conjunctiva is sufficient to increase, first, epithelial nuclear factor kappa B signaling, then, dendritic cell maturation, and finally, expansion of effector, instead of regulatory, $T$ cells in the draining lymph node, leading to disrupted ocular mucosal tolerance. We also show that damage to ocular surface nerves is required. Using pharmacological inhibitors and agonists, we identified transient receptor potential vanilloid 1 (TRPV1) channel as the receptor sensing tissue damage in the injured eye and substance $P$ released in the opposite ocular surface as the effector of the sympathetic response. Finally, blocking either step prevented subsequent ocular allergic reactions in the opposite eye in a unilateral corneal alkali burn model. This study demonstrates that both ocular surfaces are immunologically linked and suggests potential therapeutic targets for intervention.

Mucosal Immunology (2018) 11:1441-1453; https://doi.org/10.1038/s41385-018-0040-5

\section{INTRODUCTION}

Each of the two eyes in humans and other mammals is encased separately within its bony orbit, and there is no direct anatomical communication between the two compartments. The two ocular mucosal surfaces (the mucosal linings that comprise and extend from the cornea to the eyelid margins) are also physically separate, although they both ultimately drain in the nasopharynx. In line with this, the two eyes are physiologically independent from each other, even though sensory information from both organs is integrated in the brain for binocular vision.

Despite this stark anatomical and physiological separation, there is a strong body of evidence that shows that both eyes stand together when it comes to responding to injury. Perhaps the bestknown example is sympathetic ophthalmia. ${ }^{1}$ In this setting, exposure of normally sequestered choroidal antigens from the injured eye leads to sensitization, which is then followed by an intense immune response against the uninjured opposite eye. It should be noted that the involvement of the opposite eye in sympathetic ophthalmia is the indirect consequence of the systemic reach of the auto-aggressive effector T cells and not of a direct immunological link between the two eye globes. There are, however, reports of direct mechanisms for the cornea ${ }^{2,3}$ and the retina. ${ }^{4}$ Niederkorn and colleagues have shown that severing corneal nerves in one eye abrogates immune privilege of the opposite cornea through contralateral release of substance $P$
(SP) ${ }^{2,3}$ A similar phenomenon has been reported for the retina, ${ }^{4}$ and there is also evidence of a corneal-trigeminal inflammatory axis in mice. ${ }^{5}$ It could be argued that this inter-eye immunological linkage of the cornea and the retina is related to the unique immune privilege of both ocular sites, and thus that it might not apply to non-privileged ocular sites like the conjunctiva and the eyelids.

The conjunctiva is the mucosal lining of ocular surface, and from an immunological point of view, it shares many features with other mucosal surfaces. ${ }^{6}$ Its ability to induce tolerogenic immune responses to foreign antigens is paramount to preserving a functional, non-inflamed ocular surface. ${ }^{6,7}$ This property, known as mucosal tolerance, ${ }^{6}$ relies on afferent and efferent arms to and from the draining lymph node, respectively. The afferent arm begins with the epithelial lining of the ocular surface conditioning antigen-presenting cells that migrate to the draining lymph node and induce regulatory $T$ cells (Tregs). ${ }^{6}$ On the other hand, the efferent arm starts in the draining lymph node, from which Tregs recirculate until they can reach the mucosal lining and exert their anti-inflammatory activity upon encountering their cognate antigen. ${ }^{6}$ According to the prevailing mucosal immunology view, the efferent mucosal response arm of one ocular surface should bear influence on the opposite because Tregs have systemic reach through the bloodstream, but afferent arms should be completely independent from each other.

\footnotetext{
${ }^{1}$ Immunology Laboratory, Institute of Experimental Medicine (IMEX), National Academy of Medicine/CONICET, Buenos Aires, Argentina; ${ }^{2}$ Nuclear Receptors Laboratory, Institute of Experimental Biology \& Medicine (IBYME)-CONICET, Buenos Aires, Argentina and ${ }^{3}$ Microbiology, Parasitology \& Immunology Department, School of Medicine, University of Buenos Aires, Buenos Aires, Argentina

Correspondence: Jeremías G. Galletti (jeremiasg@gmx.net)
}

Received: 8 February 2018 Revised: 8 April 2018 Accepted: 15 April 2018

Published online: 4 June 2018 
1442

Intriguingly, in mice we observed by chance an altered mucosal antigenic response in the eye opposite to a single corneal lesion. This finding added to the fact that, upon having surgery on one eye, patients frequently complain of inflammation-related symptoms in the other eye. Although the latter phenomenon is usually ascribed to a subjective psychological mechanism, ${ }^{8,9}$ we hypothesized that the ocular mucosal surfaces of the two eyes, just like the corneas and the retinas, might be immunologically interdependent. Therefore, we set out to explore, first, to what extent one ocular surface can influence the mucosal immune response of the other, and then, the mechanism through which danger is sensed and conveyed to the contralateral eye.

\section{RESULTS}

A corneal injury to one eye disrupts mucosal tolerance of the opposite ocular surface

To test the effect of a unilateral corneal injury on the ocular surface of the opposite eye, we resorted to the widely employed alkali burn model, to which we incorporated instillation of ovalbumin (OVA) as a foreign antigen on either the burnt or the opposite eye (Fig. 1a). Conjunctival antigen delivery normally results in the expansion of specific Tregs from naive precursors, and although they are very scarce in number, these cells can be detected by their effect on the highly sensitive delayed-type hypersensitivity (DTH) assay (Fig. 1a). As previously described, ${ }^{7}$ conjunctival instillation of OVA led to suppression of the antigenspecific DTH response, a phenomenon usually regarded as mucosal tolerance (Fig. 1b). However, when a single corneal burn was performed and $24 \mathrm{~h}$ later OVA was instilled on the burnt eye, there was no DTH suppression; that is, mucosal tolerance in the burnt eye was abrogated. Alkali-induced injury of the ocular surface triggers a local inflammatory response ${ }^{10}$ that could expectedly imprint an immunogenic profile on the conjunctival antigen-presenting cells that migrate to the draining lymph node, ${ }^{11}$ a prerequisite for mucosal tolerance disruption. ${ }^{7}$ Although this has not been described previously, it is in line with our findings in other ocular surface inflammation models where different types of injury (eyedrop preservative toxicity, desiccating stress) abrogate mucosal tolerance. ${ }^{12-15}$ Surprisingly, instillation of OVA onto the opposite eye $24 \mathrm{~h}$ after the corneal burn was induced, an experimental condition that we originally designed as a positive control of mucosal tolerance, also failed to develop DTH suppression. We performed these experiments on Balb/c and C57BL/6 mice to rule out strain-specific findings, and since we obtained very similar results (data not shown), we continued with Balb/c mice. Then, in order to test for antigen-specific Tregs, we repeated the experiment but this time we harvested the contralateral draining lymph node cells on day 5, before immunization. These cells were then used for a local adoptive transfer (LAT) assay of DTH, ${ }^{16}$ in which they were mixed with OVA, OVA-specific effector T cells, and OVA-pulsed antigen-presenting cells. This assay is highly sensitive for antigen-specific Tregs. ${ }^{16}$ As shown in Figure 1c, T cells transferred from uninjured mice that had been instilled with OVA readily suppressed the local DTH response, whereas those obtained from the draining lymph nodes opposite to a unilateral corneal burn did not. In other words, OVAspecific Tregs were expanded in control mice but not in mice with a contralateral corneal burn. These results thus indicated that a corneal burn disrupts mucosal tolerance in the contralateral ocular surface. To corroborate this phenomenon in an independent model, we performed a corneal burn in one eye of Balb/c mice (major histocompatibility complex (MHC) haplotype d) and then we inoculated allogeneic B16 melanoma cells (which were initially derived from a C57BL/6 mouse with an MHC haplotype b) ${ }^{17}$ into the subconjunctival space of the opposite eye (Fig. 1d). The rationale was that allogeneic tumor cells in the subconjunctival space would be rejected more efficiently if mucosal tolerance was abrogated. The B16 tumor line was chosen because it is poorly immunogenic in this allogeneic transplantation model, ${ }^{18}$ thus allowing us to observe changes in conjunctival mucosal tolerance. As shown in Figure 1e, $\mathrm{f}$, conjunctival tumor growth was significantly reduced in mice that had received an alkali burn in the opposite cornea compared to uninjured control mice $(p=$ 0.03). Altogether these findings show that a corneal burn to one eye disrupts mucosal tolerance to foreign antigens in the opposite ocular surface.

A corneal injury in one eye increases epithelial nuclear factor (NF)$\mathrm{KB}$ signaling and dendritic cell (DC) maturation in the opposite conjunctiva and T-cell activation in the contralateral lymph nodes As in other mucosal linings, mucosal tolerance at the ocular surface relies on the migration of antigen-loaded DCs to the local lymph node, where they present their antigen to naive T cells. ${ }^{6}$ However, the decisive step in this process is how the conjunctival epithelium instructs DCs with either a tolerogenic or an immunogenic program before migration. ${ }^{19}$ The program imparted to DCs is highly determined by the level of NF-KB transcriptional activity in the epithelial cells ${ }^{19,20}$ : whereas basal NF-KB signaling is required for steady-state migration of tolerogenic $D C{ }_{1}{ }^{21}$ heightened epithelial NF-KB activity is required for immunogenic DCs. ${ }^{20}$ Therefore, we analyzed NF-KB activation levels by confocal microscopy in the ipsilateral and contralateral conjunctival epithelium of mice $48 \mathrm{~h}$ after a unilateral corneal burn. As expected, we observed increased nuclear translocation of the NF-KB p65 subunit, which is indicative of NF-KB activity, in the conjunctiva surrounding the corneal burn (Fig. 2a). Remarkably, a similar, simultaneous increase was also detected in the contralateral conjunctiva that could be reverted by topical instillation of an NF-KB activation inhibitor, confirming the specificity of these findings. In the ipsilateral conjunctiva, we also observed at $48 \mathrm{~h}$ postinjury the expected increase in the expression of tumor necrosis factor- $\alpha$ (TNF- $\alpha$ ) and interleukin-1 $\beta$ (IL-1 $\beta$ ), two proinflammatory cytokines that are upregulated in almost every ocular structure after an alkali burn. ${ }^{22}$ By contrast, comparable changes did not occur in the contralateral conjunctiva (Fig. 2b). These findings preclude that the observed breakdown in mucosal tolerance in the opposite ocular surface are due to inflammatory changes.

We then tested the effect of a unilateral corneal burn on conjunctival DC migration and conditioning. As shown in Figure 2c, there was an increase in the proportion of DCs in the eye-draining lymph nodes both ipsilateral and contralateral to a corneal burn induced $48 \mathrm{~h}$ earlier. In order to investigate the source of the DCs in the contralateral eye-draining lymph nodes, we resorted to a different setup. First, we painted the ocular surface cells of one eye of the mice with fluorescein isothiocyanate (FITC), and immediately after we either induced a corneal burn on the other eye or left it untreated. As shown in Figure $2 \mathrm{~d}$, there was a significant increase in the number of FITC+ DCs in the draining lymph node $24 \mathrm{~h}$ after a contralateral corneal burn. Then we injected OVApulsed DCs in the subconjunctival space of one eye of mice that had received a corneal burn in the opposite eye $24 \mathrm{~h}$ earlier, and the mice were immunized with OVA plus adjuvant $96 \mathrm{~h}$ later (Fig. 2e). Compared with uninjured animals, mice that received OVA-pulsed DCs in the subconjunctival space opposite to an already established corneal burn developed stronger antigenspecific responses, suggesting immunogenic conditioning by the local milieu. In line with the higher levels of NF-KB activity in the conjunctival epithelium and enhanced DC migration and conditioning after a single corneal burn, we also observed changes in the T-cell compartments of the draining lymph nodes on both sides. There was a comparable increase in the fraction of activated $(\mathrm{CD} 69+) \mathrm{CD} 4+\mathrm{T}$ cells on both sides $24 \mathrm{~h}$ after a unilateral corneal burn and this change was seen up to $96 \mathrm{~h}$ later (Fig. 2f). Remarkably, there was no statistically significant difference 
a

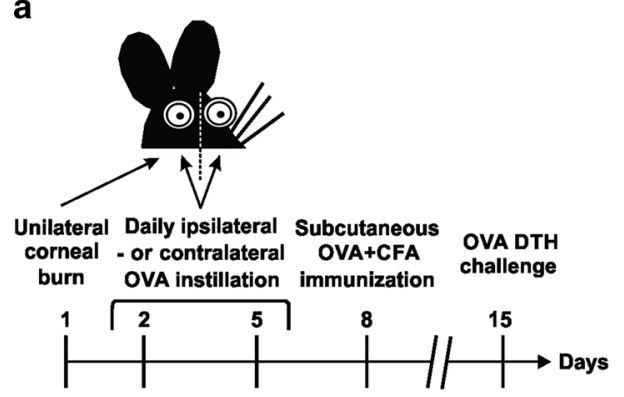

d

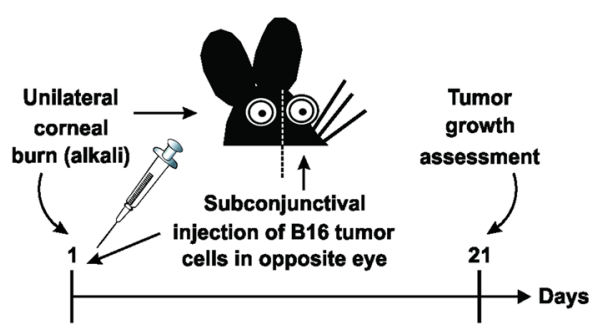

b

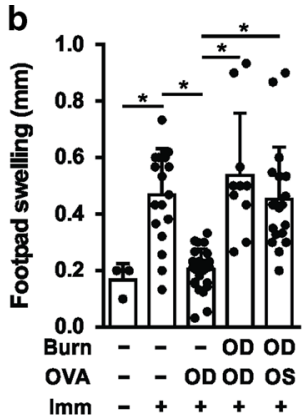

C

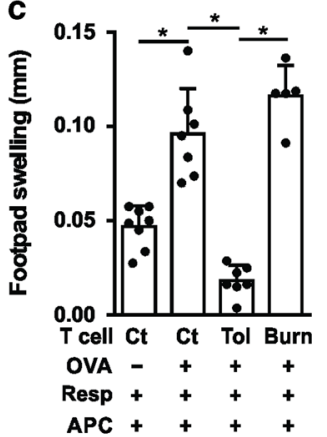

e

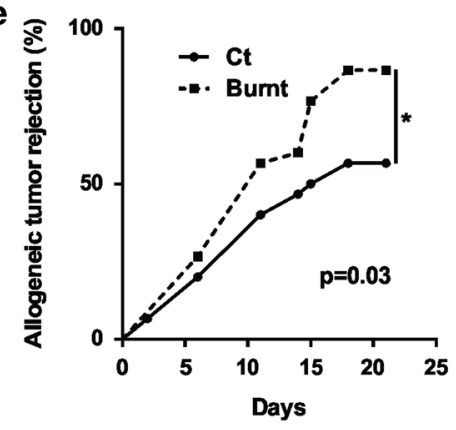

$\mathbf{f}$
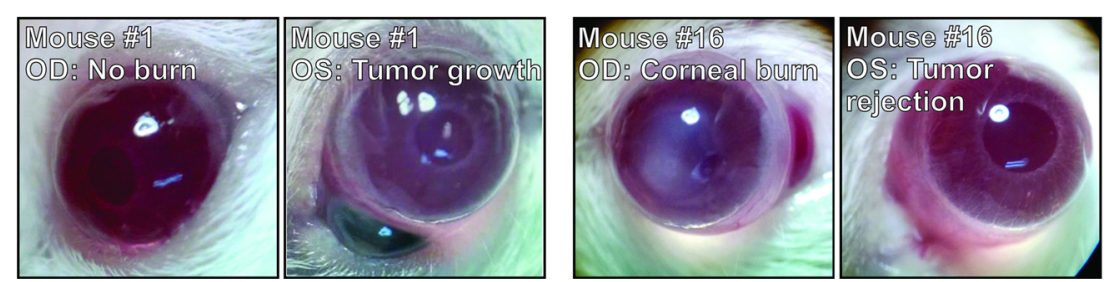

Fig. 1 A corneal injury to one eye disrupts mucosal tolerance of the opposite ocular surface. a Experimental design for assessing the ocular mucosal response to ovalbumin (OVA) in the context of a unilateral alkali-induced corneal burn. For this experiment, a corneal burn was performed in the right eye (OD), and then antigen was instilled onto either the right or left eye (OS) and s.c. immunization was performed with complete Freund's adjuvant (CFA) at the specified time points. The antigen-specific immune response was measured by footpad swelling in a delayed-type hypersensitivity (DTH) challenge. b Antigen-specific swelling in control non-immunized and immunized (Ct) mice, as well as from mice that were tolerized (Tol) by ocular instillation of OVA, or burnt and exposed to antigen on the same or on the opposite eye (Burn) mice. Footpad swelling was measured $48 \mathrm{~h}$ after s.c. OVA injection and expressed as the difference with the saline-injected contralateral footpad. Pooled data (mean \pm SD) from 6 independent experiments with 3 mice/group (two-way ANOVA with Bonferroni's correction). c Local adoptive transfer of DTH assay with submandibular lymph node T cells that were harvested on day 5 of experiment shown in a and mixed with antigen-presenting cells (APC) pulsed or not with antigen and OVA-specific responding T cells (Resp). Footpad swelling was measured 24 $\mathrm{h}$ after s.c. injection of the cells and expressed as the difference with the saline-injected contralateral footpad. Pooled data (mean \pm SD) from 3 independent experiments with 3-6 mice/group (two-way ANOVA with Dunnett's multiple comparisons test). d Experimental design for assessing subconjunctival tumor rejection in the context of a contralateral alkali-induced corneal burn. One cornea per Balb/c mouse was burnt with $\mathrm{NaOH}$ or left untreated and immediately after 150,000 allogeneic B16 melanoma cells were inoculated in the contralateral subconjunctival space. Mice were evaluated every 2-3 days for 3 weeks and tumor growth was recorded by direct inspection. e Pooled data from 3 independent experiments with 2 groups of 10 mice each $(n=60)$. Allogeneic tumor rejection rates were analyzed by log-rank (Mantel-Cox) test. $\mathbf{f}$ Representative micrographs of mouse eyes on day 21 after tumor inoculation. For all panels, asterisk $\left(^{*}\right)$ indicates a statistically significant difference by the corresponding test

between the two sides at any time point explored (Fig. 2f). In addition, there was also an increase in the expression and secretion of interferon (IFN) $-\gamma$ in lymph node cells (Fig. $2 g$, h) on both sides after a single corneal burn. Altogether these findings show that after a corneal injury in one eye, in addition to the expected ipsilateral response, there are detectable changes in at least three key elements of the contralateral mucosal immune circuit: the ocular surface epithelium activation status, the conditioning and migration of mucosal DCs, and in the T cells in the draining lymph node.

Despite the lack of lymphatic crossdrainage, a conjunctival incision is sufficient to affect the contralateral ocular surface Next, we analyzed which physiological mechanism could be mediating the observed inter-eye effect. First, we hypothesized that if lymphatic drainage from each ocular surface reached the cervical lymph nodes on both sides (crossdrainage), it would provide an anatomical basis for proinflammatory signals emanating from the injured eye to influence the antigen-loaded DCs from the opposite eye in the same lymph node. We tested this possibility by injecting a tracer protein (FITC-labeled OVA) in the subconjunctival space of one eye and analyzing lymph node cells $2 \mathrm{~h}$ later. Large granular cells (including macrophages and DCs) rapidly take up OVA by macropinocytosis and can be detected by fluorescence-activated cell sorter. As shown in Figure 3a, b, about $90 \%$ of the tracer signal was detected in the ipsilateral submandibular lymph node, and the rest went to the ipsilateral preauricular lymph node. Ocular surface-derived lymphatic crossdrainage was ruled out by the fact that the contralateral cervical lymph nodes had the same negligible signal as inguinal lymph 

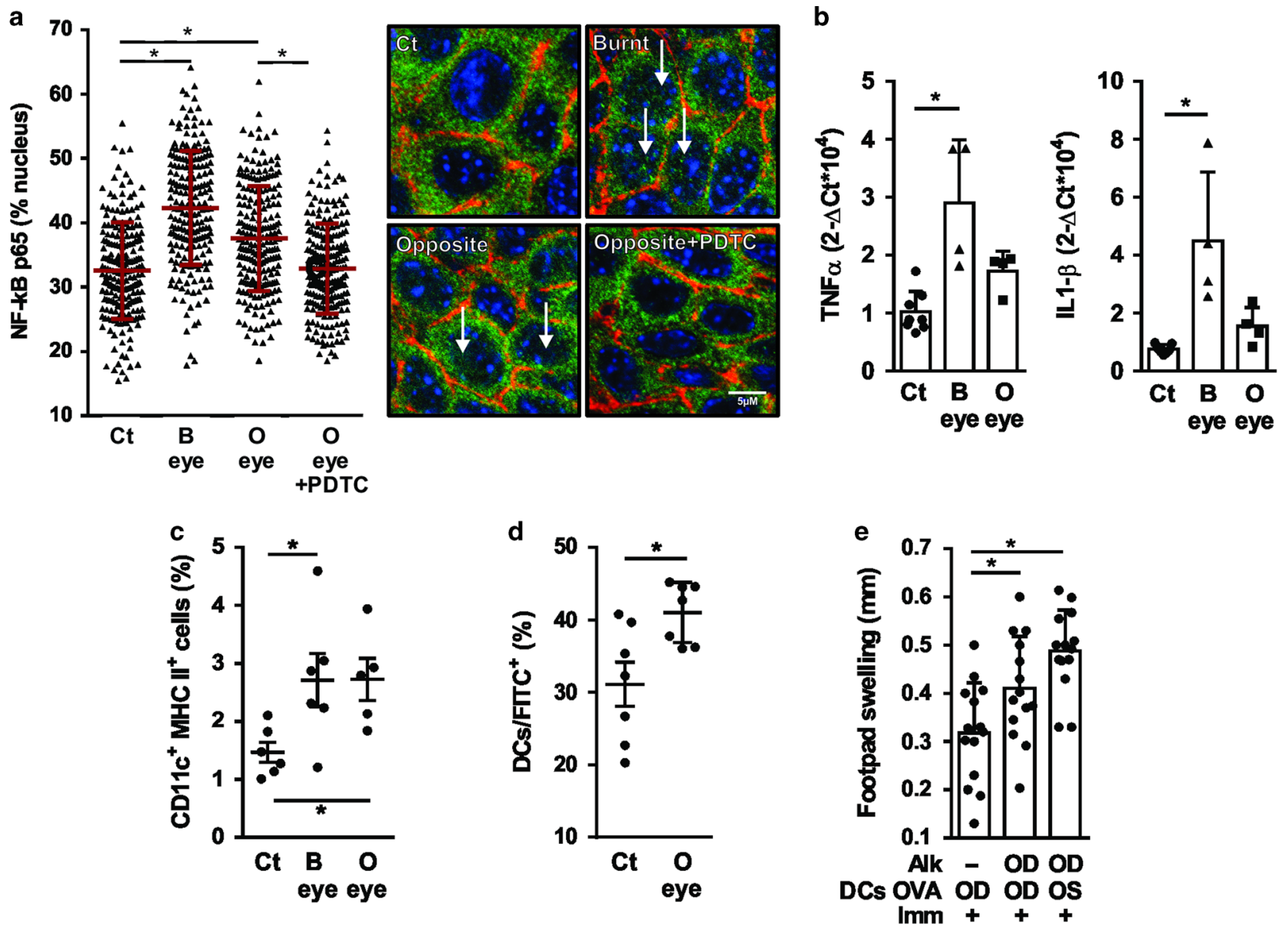

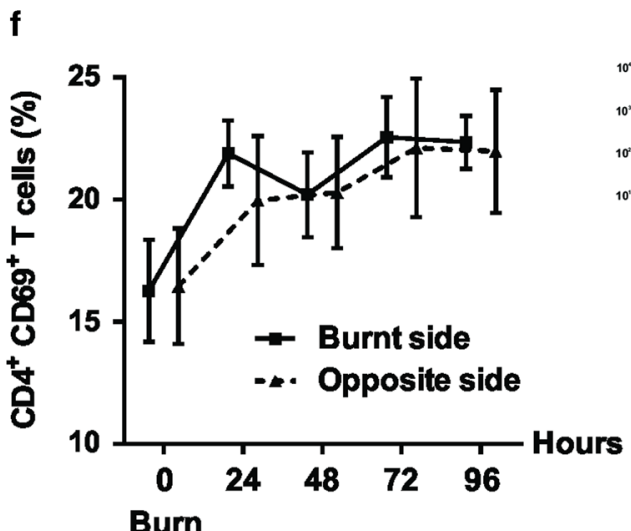

nodes. The slight but statistically significant increase in fluorescence from background levels observed in all tested lymph nodes could be explained by blood-borne spread. Then we explored if a neural circuit similar to that shown to link corneal immune privilege in both eyes could also apply to the mucosal immune response of the ocular surface. ${ }^{5}$ As Niederkorn and colleagues demonstrated that damage to corneal nerves was responsible for initiating the contralateral disruption in corneal immune privilege, ${ }^{2,3}$ we explored whether severing conjunctival nerve endings could also affect the opposite ocular surface. Thus, we performed a $180^{\circ}$ circumferential incision of the bulbar conjunctiva on one eye, and then we instilled OVA on the opposite eye starting the following day for 4 days, as for the previous experiments (Fig. 3c). As shown in Figure $3 \mathrm{~d}$, a unilateral conjunctival incision was sufficient to disrupt mucosal tolerance in the opposite ocular surface, the same finding observed for a unilateral corneal burn. Altogether these results suggest that a physiological pathway other than the conventional lymphatic drainage to lymph nodes is responsible for the inter-eye effect.

Transient receptor potential vanilloid 1 (TRPV1)-initiated signaling in one eye disrupts mucosal tolerance in the opposite ocular surface by inducing contralateral release of SP

Given that a conjunctival incision was sufficient to elicit the contralateral ocular response, we suspected that an inter-eye neural arc could be involved, as has been suggested for the cornea ${ }^{2}$ and the retina. ${ }^{4}$ Since the vanilloid receptor 1 (TRPV1) is known to mediate neuroinflammatory responses elsewhere ${ }^{23}$ and it is highly expressed in the ocular surface nerve terminals, ${ }^{24}$ we hypothesized that this ion channel could be involved in the 
Fig. 2 A corneal injury in one eye leads to marked changes in the opposite ocular surface and the contralateral lymph nodes. a Dot plot (left) and representative confocal micrographs (right) of nuclear localization of NF-kB p65 protein (green) relative to individual cell expression (blue: TO-PRO-3, red: phalloidin) in the conjunctival epithelium of control (Ct) or injured mice, either from the burnt (B) or from the opposite (O) eye, taken $48 \mathrm{~h}$ after the lesion was induced. Some mice received a NF- $\mathrm{kB}$ activation inhibitor on the opposite eye immediately before and until the conjunctiva was harvested (O eye+PDTC). Mean \pm SD of at least 200 cells analyzed from samples from 3 mice/group (representative example of 3 independent experiments), analyzed by one-way ANOVA with Bonferroni's correction. b Tumor necrosis factor (TNF)- $\alpha$ and interleukin (IL)$1 \beta$ mRNA levels assessed by qRT-PCR in the conjunctiva of control $(\mathrm{Ct})$ mice and of mice that had received a single alkali-induced corneal burn $48 \mathrm{~h}$ earlier. Conjunctivas from the burnt (B) and opposite (O) eyes were analyzed separately. Results were normalized to GAPDH housekeeping gene and represented as relative units $\left(2-\Delta \mathrm{Ct} \times 10^{4}\right)$. Pooled data (mean $\pm \mathrm{SD}$ ) from 3 independent experiments with 3 or more mice/group (one-way ANOVA with Dunnett's multiple comparisons test). c Percentage of CD11c+ MHC-II+ cells in the submandibular lymph nodes of control $(\mathrm{Ct})$ or injured mice harvested $48 \mathrm{~h}$ after a unilateral alkali-induced corneal burn. Lymph nodes from the burnt (B) and opposite (O) sides were analyzed separately. Mean + SEM of a representative experiment with 6 mice/group (3 independent experiments), analyzed by one-way ANOVA with Dunnett's multiple comparisons test. d Percentage of fluorescein isothiocyanate (FITC)-labeled CD11c+ cells in eye-draining lymph nodes harvested $24 \mathrm{~h}$ after ocular surface painting from control $(\mathrm{Ct})$ mice or with a simultaneous alkali-induced corneal burn in the opposite $(\mathrm{O})$ eye. Mean + SEM of a representative experiment with 8 mice/group (3 independent experiments), analyzed by Student's $t$-test. e Antigen-specific swelling in a delayed-type hypersensitivity assay performed after systemic immunization with adjuvant $(\mathrm{Imm})$ of mice that received ovalbumin-pulsed dendritic cells (DCs OVA) in the subconjunctival space of one eye and had an alkali-induced corneal burn in the same or the opposite eye (OD and OS, right and left eye, respectively). Footpad swelling was measured $48 \mathrm{~h}$ after s.c. OVA injection and expressed as the difference with the saline-injected contralateral footpad. Pooled data (mean \pm SD) from 3 independent experiments with 4-6 mice/group (two-way ANOVA with Dunnett's multiple comparisons test). f Number of CD4+ CD69+ T cells in eyedraining lymph nodes of mice taken at different time points and that received an alkali-induced corneal burn in one eye (time 0). Lymph nodes from each side (burnt and opposite) were analyzed separately. Pooled data (mean \pm SD) from 3 independent experiments with 3 mice/ time point (two-way ANOVA). $\mathbf{g}$ Interferon (IFN)- $\gamma$ mRNA levels assessed by qRT-PCR and $\mathbf{h}$ interferon- $\gamma$ production determined by ELISA in whole-cell suspensions or purified T cells, respectively, from eye-draining lymph node cells of control mice (Ct) or mice that had received a single alkali-induced corneal burn $48 \mathrm{~h}$ earlier. Lymph nodes from each side [burnt (B) and opposite (O)] were analyzed separately. For mRNA, results were normalized to GAPDH housekeeping gene and represented as relative units $\left(2-\Delta \mathrm{Ct} \times 10^{4}\right)$. Data (mean \pm SD) from 3 independent experiments with 3 or more mice/group (two-way ANOVA with Dunnett's multiple comparisons test). For all panels, asterisk $\left({ }^{*}\right)$ indicates a statistically significant difference by the corresponding test

afferent signaling of the aforementioned inter-eye reflex. Moreover, TRPV1 signaling is linked to SP release, which has been shown to mediate the corneal and retinal inter-eye reflexes. ${ }^{2-4}$ To this aim, we instilled capsaicin, a specific TRPV1 agonist, repeatedly onto one eye (4 times a day for 4 days) and applied OVA as before on the opposite eye (Figure 4a). As shown in Figure. $4 \mathrm{~b}$, repeated unilateral capsaicin stimulation was sufficient to disrupt mucosal tolerance to OVA in the opposite ocular surface. As a control for non-neurogenic inflammation, we injected complete Freund's adjuvant (CFA) in the subconjunctival space of one eye, which did not affect mucosal tolerance in the opposite eye. Moreover, the capsaicin-induced contralateral effect was blocked by a specific SP antagonist (fosaprepitant, a clinically approved neurokinin 1 receptor antagonist) instilled on the opposite eye (Fig. 4b). In line with these findings, unilateral capsaicin delivery significantly increased NF-KB activation levels in the conjunctival epithelium of both eyes $48 \mathrm{~h}$ after repeated instillation, and this effect could also be prevented in the opposite eye by topical SP antagonist administration (Fig. 4c). Altogether these results show that TRPV1 signaling in one eye disrupts mucosal tolerance in the contralateral ocular surface through release of SP. As conjunctival epithelial cells are known to express functional SP (neurokinin 1) receptors, ${ }^{25}$ we tested whether SP in and of itself was able to activate NF-KB signaling in cultured conjunctival epithelial cells. As shown in Figure 4d, both SP and benzalkonium chloride (a known NF-KB activator ${ }^{13}$ ) readily induced nuclear translocation of NF-KB p65, where it exerts its transcriptional regulation.

We then tested the pathophysiological relevance of this intereye neurogenic inflammatory reflex in the model of unilateral alkali-induced corneal burn. To this aim, we soaked one ocular surface with either of two TRPV1 antagonists (SB-366791 and $\mathrm{BCTC}$ ) before inducing the corneal burn as previously described, and we also instilled a SP blocker on the opposite eye (Fig. 5a). In this setup, both TRPV1 antagonists prevented the contralateral disruption of ocular surface mucosal tolerance, highlighting the role of this signaling pathway in the neural arc's afferent arm (Fig. 5b, only SB-366791 data are shown). Conversely, instillation of SP antagonist on the eye opposite to the unilateral corneal burn also blocked the effect, confirming that this neurokinin mediates the efferent arm of the response in the model (Fig. 5b). In addition, in the context of a unilateral alkali-induced corneal burn, both blockade of TRPV1 signaling in the burnt eye and of the SP receptor in the opposite eye led to decreased NF-KB activation levels in the conjunctival epithelial of the opposite eye (Fig. 5c). Overall, these results show that the disruption of the mucosal tolerogenic response in the eye opposite to the corneal burn is initiated by TRPV1 signaling in the injured ocular surface and is mediated by SP release in the opposite ocular surface.

After a single corneal burn, breakdown of mucosal tolerance favors an allergic conjunctival reaction in the opposite ocular surface

In order to test how the described immune disruption in the contralateral ocular mucosal surface could have a clinical effect, we resorted to a modified murine model of allergic conjunctivitis to OVA. We have previously shown that ocular mucosal tolerance prevents mice from developing allergic reactions in this model [13], and here we hypothesized that a unilateral corneal burn should abrogate this protective homeostatic mechanism in the opposite eye. To this aim, we instilled OVA onto one of the eyes of mice that had received a corneal burn in the opposite eye the day before (Fig. 6a). Then we actively immunized the mice with OVA +alum, and finally, we instilled OVA again for several days on the same eye that had previously received the antigen in order to elicit an allergic response opposite to the corneal burn. As shown in Figure $6 b-d$, control mice with neither a corneal burn nor prior ocular exposure to OVA developed a strong ocular allergic response to OVA after systemic immunization, as assessed by clinical score and OVA-specific immunoglobulin E ( $\operatorname{lgE}$ ) serum levels. As we have previously reported for bilateral instillation, ${ }^{13}$ unilateral eye exposure to OVA also led to mucosal tolerance in this system, which prevents subsequent allergic reactions. However, this protection was not observed in the context of a contralateral corneal burn, highlighting the disruptive influence on ocular mucosal tolerance. Remarkably, the pro-allergenic conditioning on the ocular surface opposite to the corneal burn could be completely prevented by blocking afferent TRPV1 signaling in the burnt eye with a topical TRPV1 antagonist or by interfering with efferent SP signaling in the opposite eye 


\section{6}

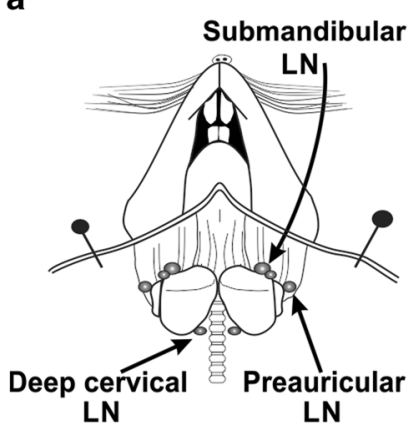

C

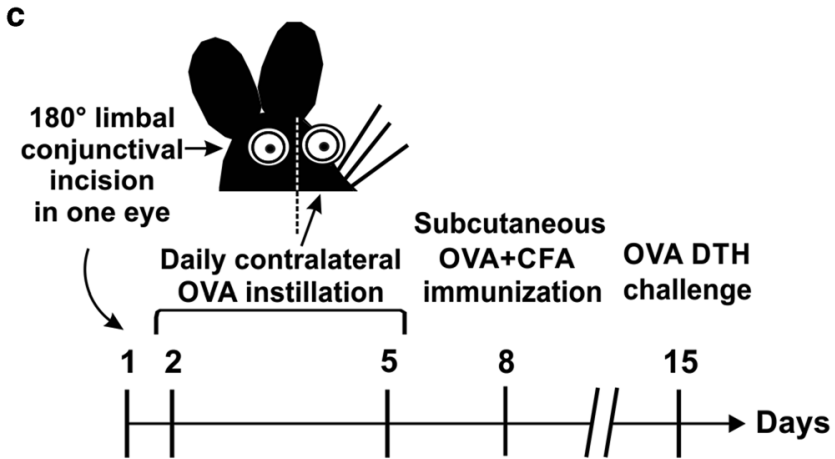

b

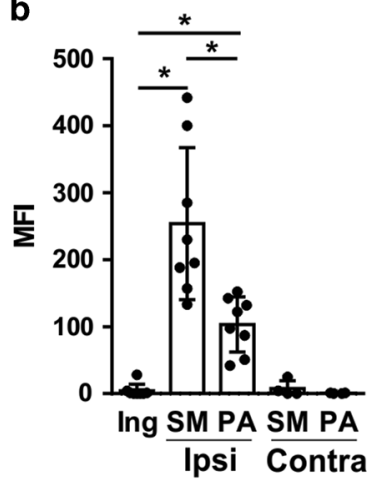

with a topical SP receptor antagonist. Altogether these results show how a corneal injury can affect the clinical course of an allergic reaction in the opposite ocular surface and, more importantly, that TRPV1 and SP-mediated signaling pathways are involved in this inter-eye neural circuit.

\section{DISCUSSION}

The two eye globes are known to be immunologically interdependent, ${ }^{2-5}$ and here we show that the ocular surfaces are encompassed within this functional link. The inter-eye influence involves a neurogenic inflammatory reflex that relies on TRPV1 signaling in the afferent arm and SP release in the effector arm. Its consequence is the sympathetic disruption of homeostatic mucosal tolerance in the contralateral ocular surface after a singleeye injury severe enough to affect nerve endings (Fig. 7). These findings implicate several pathophysiological considerations of interest.

First, the inter-eye effects for the retina and cornea reported elsewhere ${ }^{2-5}$ and for the ocular surface shown here should not be confounded with sympathetic ophthalmia, a distinct pathological entity. ${ }^{1}$ The latter involves the loss of immune privilege for retinal and/or choroidal antigens upon penetrating trauma to one eye that ultimately leads to a destructive autoimmune inflammation of the opposite eye. ${ }^{1,26}$ The disease process bears resemblance with sympathetic orchitis, an autoimmune inflammation of the testes that can be elicited by unilateral testicular injury. ${ }^{27}$ Of note, both conditions are forms of organ-specific autoimmunity that target self-antigens that are usually ignored by the immune system because of well-established organ-blood barriers. ${ }^{1,28}$ By contrast, the inter-eye phenomenon we are currently describing represents rapid contralateral proinflammatory responses that do not correlate with specific disease entities but nonetheless contribute to the pathophysiology of ocular disease. The fast onset (around $24 \mathrm{~h}$ ) of the contralateral effect and the lack of lymphatic crossdrainage for the ocular surface point out to a neurogenic inflammatory reflex, and central neuroinflammation in response to a corneal burn has been reported in mice. ${ }^{5}$ Moreover, there is a history of incidental control observations, as was our case, that were unanticipated developments of different experiments involving peripheral nerve lesions. ${ }^{29}$ These findings are not limited to the eye, and there seems to be a widespread side-to-side correlation in peripheral neurogenic responses that are explained by commissural interneurons in the spinal cord and the brainstem. ${ }^{30}$

Second, here we show that activation of the heat and protonsensitive TRPV1 channel is required to initiate the inter-eye response in the ocular surface. TRPV1 is expressed on polymodal nociceptors, which are the majority of the peripheral sensory fibers that innervate the eye from the trigeminal ganglion. ${ }^{31}$ These neuron endings preferentially also express SP and calcitonin-generelated peptide, ${ }^{32}$ and TRPV1 is the main target for many signaling pathways activated by inflammatory mediators. ${ }^{31}$ Of note, nerve damage leads to changes in TRPV1 expression and signal transduction, which in turn contribute to the abnormal nerve impulse bursts that are observed in nociceptor fibers after peripheral nerve injury. ${ }^{33}$ Remarkably, actual nerve damage in the cornea, ${ }^{2}$ retina, ${ }^{4}$ and also the conjunctiva seems to be required for the different inter-eye effects to be elicited, which suggests that the contralateral immune priming does not take place upon any provocation but severe danger. Although this might make sense from an evolutionary perspective, it should be noted that large corneal and conjunctival incisions are routinely performed in clinical practice, and there is ample evidence of increased dry eye and allergy symptoms in patients who have undergone ocular surgery. ${ }^{34}$ Immune privilege is thought to have evolved to preserve the eye and the brain from the deleterious effects of unharnessed inflammation. ${ }^{35}$ In this regard, SP is a well- 
a

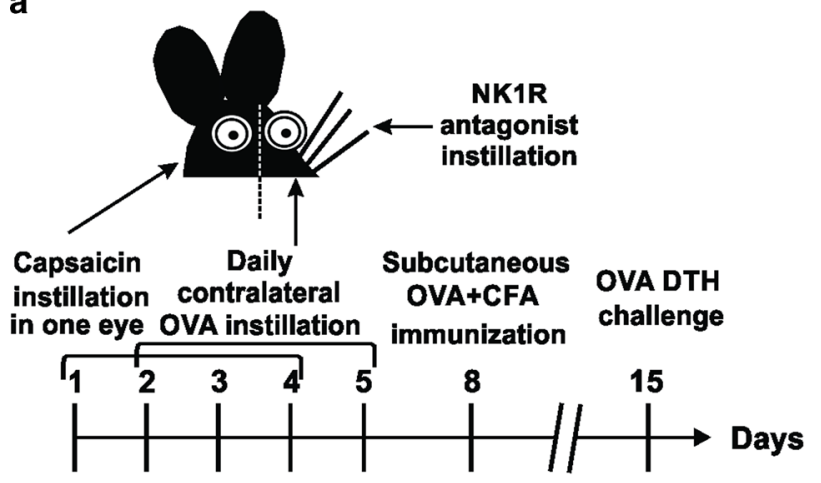

b

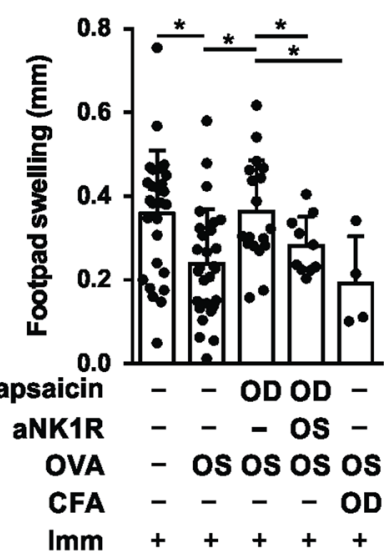

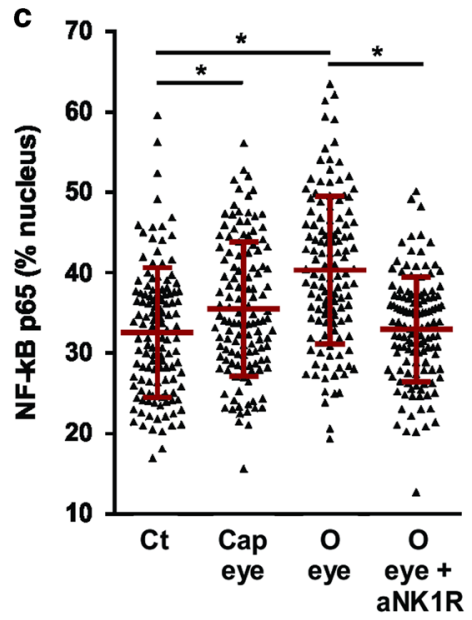

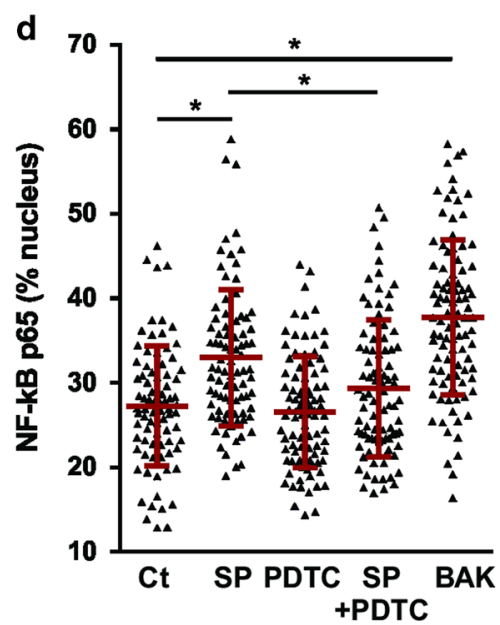

characterized mediator of neurogenic inflammation after traumatic brain injury, ${ }^{36}$ and all SP-expressing corneal neurons in the trigeminal ganglion also express TRPV $1 .{ }^{32}$ Epithelial cells, DCs, and $T$ cells express functional SP receptors, and this neuropeptide exerts numerous proinflammatory functions. ${ }^{37}$ Here we show that it enhances NF-KB signaling in conjunctival epithelial cells, and this neuropeptide also favors DC maturation. ${ }^{38}$ SP plays an important role in ocular surface epithelial barrier function and DC homeostasis, ${ }^{39}$ thus it is not striking that its release upon contralateral TRPV1 activation leads to mucosal tolerance disruption in our model.
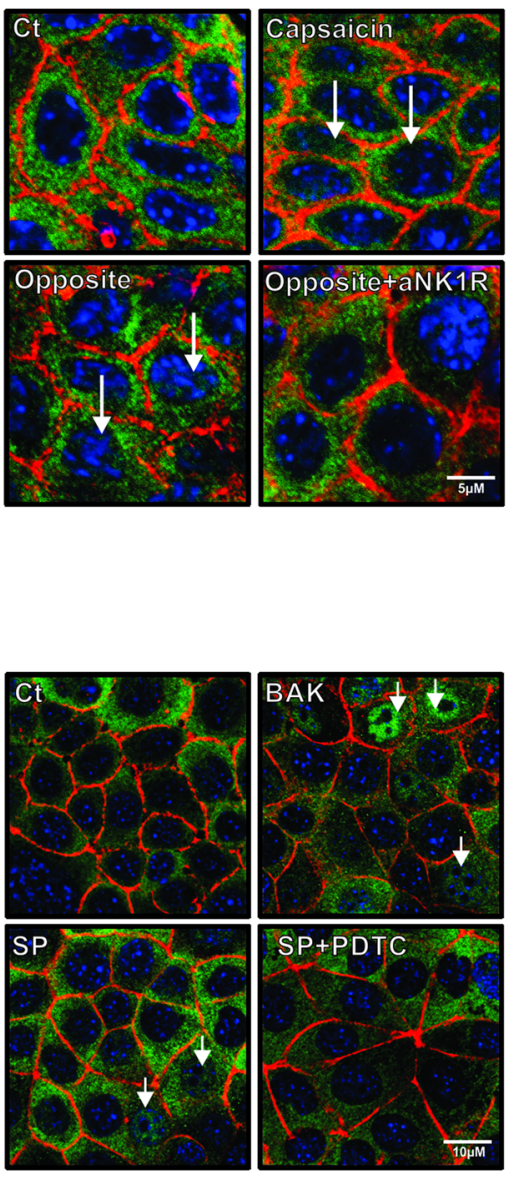

Third, the proposed inter-eye neurogenic inflammatory axis might explain the increased incidence of pain and discomfort in the second eye after bilateral ocular surgery., ${ }^{8,9}$ Ocular surface mucosal tolerance is a homeostatic mechanism by which the conjunctiva actively regulates local and systemic immune responses to the array of exogenous antigens to which it is constantly exposed. ${ }^{6}$ Mucosal tolerance involves the expansion and activation of antigen-specific Tregs, and their effect can be long lasting. Dry eye is an ocular surface disorder that is fueled by altered conjunctival tolerance. ${ }^{14,15,40}$ Intriguingly, eye surgeons observe little acute local inflammatory reactions to clean-cut 
Fig. 4 TRPV1-initiated signaling in one eye disrupts mucosal tolerance in the opposite ocular surface by inducing contralateral release of substance P. a Experimental design for dissecting the inter-eye neurogenic inflammatory response affecting the ocular mucosal response to ovalbumin (OVA). From days 1 to 4, capsaicin was repeatedly applied to the right eye (OD) while at the same time saline or a substance $P$ blocker was instilled on the left eye (OS). Antigen was instilled on the left eye from days 2 to 5 , and then s.c. immunization was performed with complete Freund's adjuvant (CFA). The antigen-specific immune response was measured by footpad swelling in a delayed-type hypersensitivity (DTH) challenge. b Antigen-specific swelling in control immunized and tolerized mice that only received OVA and in mice that received capsaicin (Cap) and/or substance P blocker (aNK1R) on either eye before immunization (Imm). Some mice were injected subconjunctivally with CFA. Footpad swelling was measured $48 \mathrm{~h}$ after s.c. OVA injection and expressed as the difference with the salineinjected contralateral footpad. Pooled data (mean \pm SD) from 4 independent experiments with at least 3 mice/group (two-way ANOVA with Bonferroni's correction). c Dot plot (left) and representative confocal micrographs (right) of nuclear localization of NF- $\mathrm{BB}$ p65 protein (green) relative to individual cell expression (blue: TO-PRO-3, red: phalloidin) in the conjunctival epithelium of mice that received saline (Ct) or capsaicin (Cap) on the right eye. Both eyes from each mouse were harvested $48 \mathrm{~h}$ after daily instillation and analyzed separately. Some animals also received aNK1R (PDTC) on the opposite (O) eye. Mean \pm SD of at least 100 cells analyzed from samples from 3 mice/group (representative example of 3 independent experiments), analyzed by one-way ANOVA with Bonferroni's correction. d Dot plot (left) and representative confocal micrographs (right) of nuclear localization of NF-KB p65 protein stained as for $c$ and obtained from cultures of murine conjunctival epithelial cells exposed for $15 \mathrm{~min}$ to fresh medium (Ct), NF-kB activation inhibitor (PDTC), substance P (SP), a combination of both, and benzalkonium chloride (BAK). Mean \pm SD of at least 100 cells from 3 replicates (representative example of 3 independent experiments), analyzed by one-way ANOVA with Bonferroni's correction. For all panels, asterisk (*) indicates a statistically significant difference by the corresponding test

corneal and conjunctival incisions, but patients complain of pain and ocular surface symptoms in the second eye more frequently in the long term. Here we show that the disruption of contralateral mucosal tolerance favors ocular allergic reactions in mice and that this effect is initiated by TRPV1 signaling and is mediated by SP. Moreover, it is possible that a unilateral corneal lesion severe enough to affect nerve endings or a surgical procedure might worsen a pre-existing ocular surface disease not only in the said eye but also in the opposite. There is evidence of a contralateral immune response in patients with a unilateral infectious keratitis, as assessed by changes in dendritiform cell numbers in the unaffected cornea. ${ }^{41}$ Thus these results add to other reports from animal models and human disease that the eye globes are not separate from an immune perspective, and therefore special considerations should be taken when dealing with such clinical situations.

In conclusion, there is evidence that both ocular surfaces are functionally linked in their ability to detect and respond to danger by a neural reflex arc in mice, and this probably applies to humans as well. The identification of TRPV1 as a key sensor could be of use for therapeutic intervention, as well as the effector role of SP release. Finally, the importance of considering both eyes (and perhaps other paired organs and structures) as one functional unit cannot be sufficiently stressed.

\section{MATERIALS AND METHODS}

Mice

Balb/c (BALB/CAnNCrl) and C57BL/6 (C57BL/6NCrl) mice were originally obtained from Charles River Laboratories (Wilmington, MA, USA), then bred and maintained at the Institute of Experimental Medicine conventional animal facility. All mice were 6-8-week old at the beginning of the experiments, and all protocols were approved by the Institute of Experimental Medicine animal ethics committee and adhered to the Association for Research in Vision and Ophthalmology Statement for the Use of Animals in Ophthalmic and Vision Research.

\section{Reagents and antibodies}

All chemical and biological reagents used were from SigmaAldrich (Buenos Aires, Argentina) unless otherwise specified. Grade V OVA was used in all experiments. A TRPV1 agonist (capsaicin, CAS number: 404-86-4), two TRPV1 antagonists (BCTC, CAS number: 393514-24-4; SB-366791, CAS number: 472981-92-3), and a NK1R antagonist (fosaprepitant, Merck, Kenilworth, NJ, USA) were included in some experiments. Fluorochrome-tagged antibodies were from BioLegend (San Diego, CA, USA) unless otherwise specified. TRIzol reagent for RNA extraction and SYBR Green PCR Master Mix for quantitative real-time polymerase chain reaction (qRT-PCR) were from Invitrogen (Waltham, MA, USA), whereas MMLV RT for CDNA synthesis was obtained from Promega (Fitchburg, WI, USA).

Mouse model of unilateral corneal burn

Mice were anesthetized using $100 \mathrm{mg} / \mathrm{kg}$ ketamine and $10 \mathrm{mg} / \mathrm{kg}$ xylazine, and deep anesthesia was confirmed by a toe pinch test. One proparacaine hydrochloride $0.05 \%$ (Poen Laboratories, Buenos Aires, Argentina) eye drop was applied to each cornea for $1 \mathrm{~min}$ and carefully dried. Alkali burns were performed on one eye by applying a $2 \mathrm{~mm}$ diameter filter paper disk soaked with $1 \mathrm{~N}$ $\mathrm{NaOH}$ on the center of the cornea for $20 \mathrm{~s}$ with the aid of forceps under a surgical microscope. Then the filter paper disk was removed and the eye was thoroughly washed with $20 \mathrm{ml}$ sterile saline, as described elsewhere. ${ }^{22,42}$ Both eyes were protected from desiccation with polyacrylic acid eye gel (Poen Laboratories, Buenos Aires, Argentina).

Ocular instillation of TRPV1/NK1R agonist/antagonist and OVA and immunization for DTH assays

For some experiments, starting $1 \mathrm{~h}$ before the unilateral corneal burn on day 1 , mice received $100 \mu \mathrm{g} / \mathrm{ml}$ of TRPV 1 antagonist (either SB-366791 or BCTC, Sigma-Aldrich) on the burnt eyes or 10 $\mathrm{mg} / \mathrm{ml} \mathrm{NK1R}$ antagonist on the opposite eyes, delivered topically in a volume of $5 \mu$ to the conjunctiva and continued for 4 days, 4 times/day. On day 2 , mice were instilled with $5 \mu \mathrm{l}$ of $2 \mathrm{mg} / \mathrm{ml}$ OVA on the burnt or the opposite eye, twice daily for 3 days. In other experiments, starting on day 1 mice received either $5 \mu \mathrm{l}$ of $1 \mathrm{mg} /$ $\mathrm{ml}$ capsaicin in maize oil or vehicle alone in one eye, 4 times/daily for 4 days, and NK1R antagonist in the opposite eye as previously detailed. In all experiments, $0.1 \mathrm{ml}$ of 1:1 phosphate-buffered saline (PBS):CFA emulsion containing $100 \mu \mathrm{g}$ OVA were injected subcutaneously in the flank on day 8 , and then on day 15 , heataggregated OVA (100 $\mu \mathrm{g}$ in PBS) and PBS alone were injected in a volume of $35 \mu \mathrm{l}$ into the right and left foot pads, respectively. Antigen-induced swelling was measured $48 \mathrm{~h}$ later with a dial thickness gauge as the mean difference in thickness between the right and left foot pads of each mouse. In one experiment, mice were anesthetized as described previously and then injected $10 \mu \mathrm{l}$ of 1:1 PBS:CFA emulsion into the subconjunctival space of one eye through a $30 \mathrm{G}$ needle under a surgical microscope. Mice were inspected at least every other day for signs of distress or pain. None of the animals developed serious inflammatory reactions (conjunctival ulceration or ocular perforation) or exhibited signs of distress to warrant premature termination of the experiment. 
a

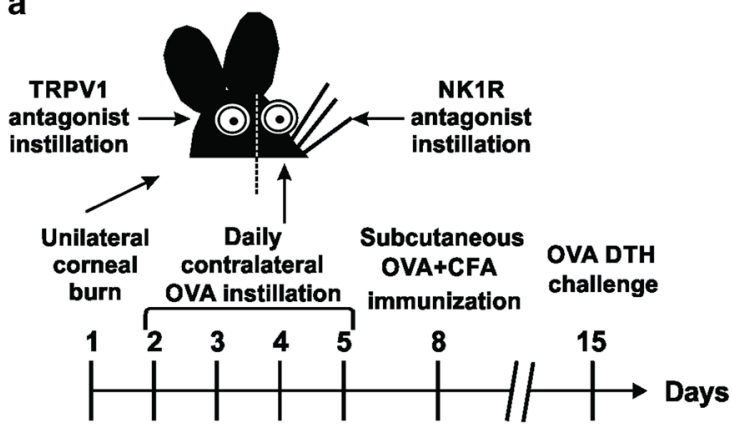

b

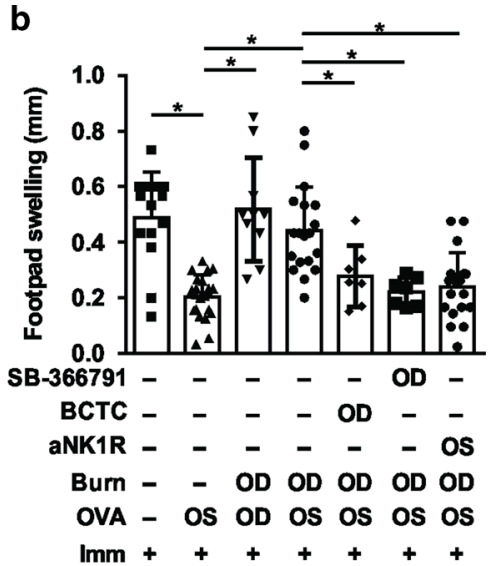

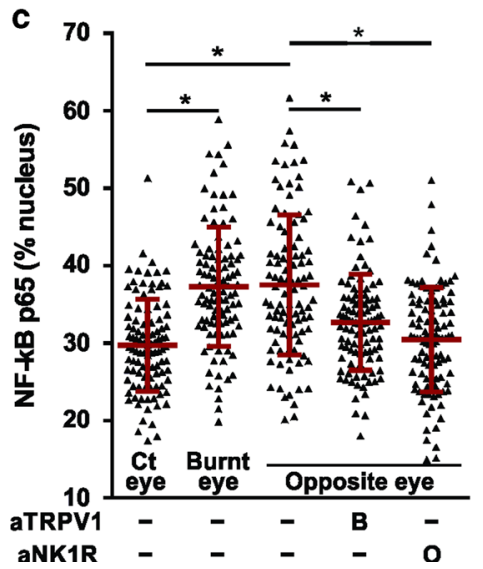

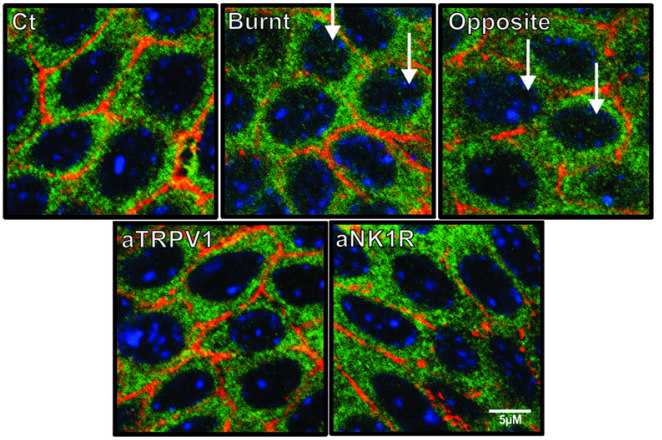

Fig. 5 TRPV1 signaling in the injured eye and SP release in the contralateral eye mediate sympathetic ocular mucosal tolerance disruption after a unilateral corneal burn. a Experimental design for dissecting the inter-eye neurogenic inflammatory reflex contribution to the contralateral ocular mucosal response to ovalbumin (OVA) in the context of a corneal burn. On day 1, either of two TRPV1 blockers (SB-366791 and BCTC, respectively) were administered repeatedly to the right eye (OD) and/or a substance P blocker (aNK1R) was repeatedly applied on the left eye (OS) of mice $1 \mathrm{~h}$ before inducing a corneal burn in the right eye. Antigen (OVA) was instilled on the left eye from days 2 to 5 , and then s.c. immunization (Imm) was performed with complete Freund's adjuvant. The antigen-specific immune response was measured by footpad swelling in a delayed-type hypersensitivity (DTH) challenge. b Antigen-specific swelling measured $48 \mathrm{~h}$ after s.c. OVA injection and expressed as the difference with the saline-injected contralateral footpad. Pooled data (mean \pm SD) from 4 independent experiments with at least 3 mice/group (two-way ANOVA with Bonferroni's correction). c Dot plot (left) and representative confocal micrographs (right) of nuclear localization of NF-KB p65 protein (green) relative to individual cell expression (blue: TO-PRO-3, red: phalloidin) in the conjunctival epithelium of mice from experiment a. Both eyes from each mouse (burnt and opposite) were harvested $48 \mathrm{~h}$ after initiation of the experiment and analyzed separately. Mean \pm SD of at least 100 cells analyzed from samples from 3 mice/group (representative example of 3 independent experiments), analyzed by one-way ANOVA with Bonferroni's correction. For all panels, asterisk (*) indicates a statistically significant difference by the corresponding test

\section{LAT assays}

T cells from submandibular lymph nodes of mice with a unilateral corneal burn were mixed with T cells from OVA-immunized mice and OVA-pulsed antigen-presenting cells (T cell-depleted splenocytes from naive mice) at a 1:1:1 ratio in PBS, and $35 \mu$ l of the resulting cell suspension containing a total of $3 \times 10^{6}$ cells were injected into the footpads of naive mice. Footpad thickness was recorded before and $24 \mathrm{~h}$ after cell injection by a masked observer, and swelling calculated accordingly.

Subconjunctival tumor rejection assay

B16 melanoma cells were maintained and harvested at logarithmic growth as detailed elsewhere. ${ }^{17}$ Balb/c mice were anesthetized and corneal burns were induced on left eyes as previously described. Then $1.5 \times 10^{5}$ B16 melanoma cells in $30 \mu \mathrm{l}$ PBS were inoculated into the subconjunctival space of the right eye through a $30 \mathrm{G}$ needle under a surgical microscope. Both eyes were protected from desiccation as previously described. Tumor growth was assessed by two masked observers by inspection under a surgical microscope every 2-3 days until day 21 (end point). B16 melanoma cells grow as non-pigmented cells in vitro but develop dark pigmentation in vivo. A local, non-pigmented inflammatory reaction at the puncture site was evident in some eyes during the first 4-5 days, whereas pigmented clumps were detectable in the conjunctiva starting on day 7. Most eyes with punctate pigment developed one or more raised pigmented lesions (tumors) by days 10-15. The presence of at least one such conjunctival tumor on day 21 was counted as positive tumor growth. Mice with excessive tumor growth (extraocular extension, tumor ulceration, or impaired eyelid closure) were sacrificed before the end point and also counted as positive tumor development.

Ocular antigenic challenge and assessment of allergic response After OVA and antagonist instillations from days 1 to 5 , mice were immunized intraperitoneal on days 8 and 15 with $0.5 \mathrm{ml}$ of $400 \mu \mathrm{g} /$ $\mathrm{ml} \mathrm{OVA}+4 \mathrm{mg} / \mathrm{ml}$ aluminum hydroxide suspension. On day 21 , mice were challenged daily with $5 \mu \mathrm{l}$ of $250 \mathrm{mg} / \mathrm{ml}$ OVA on one eye for 10 days. The eyes were photographed $30 \mathrm{~min}$ after the instillation every 2 days. At the end of the experiment, clinical inflammation was assessed by three masked observers by grading 
a
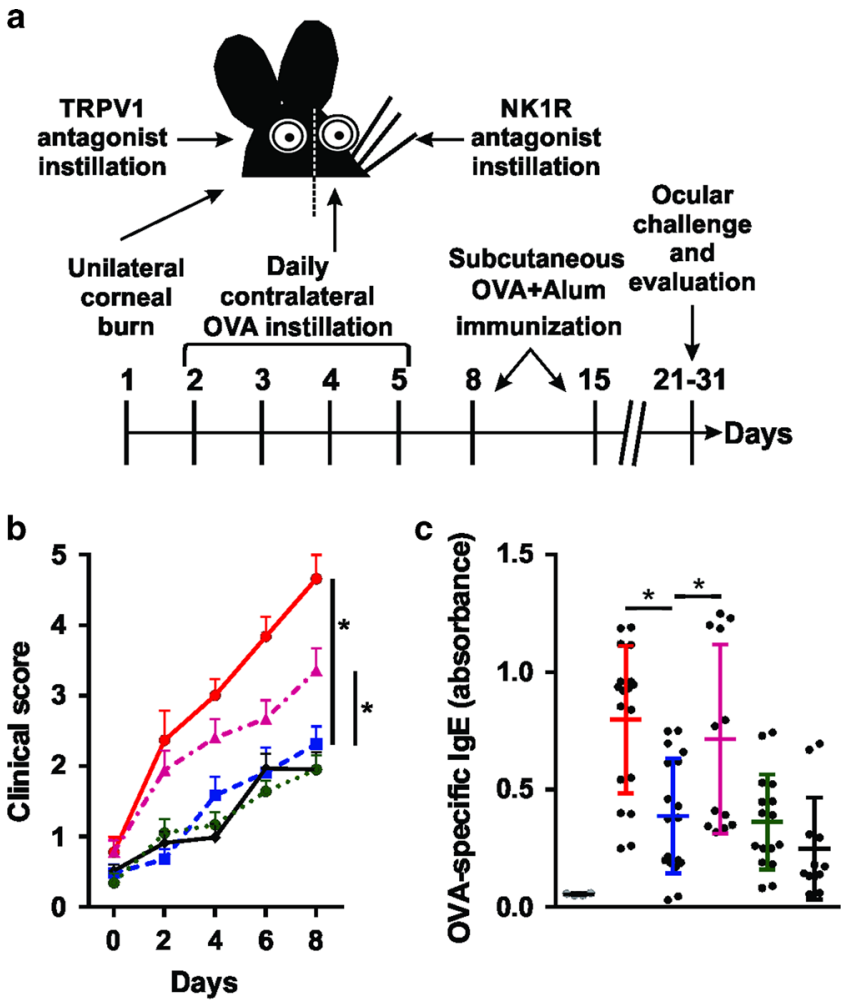

d
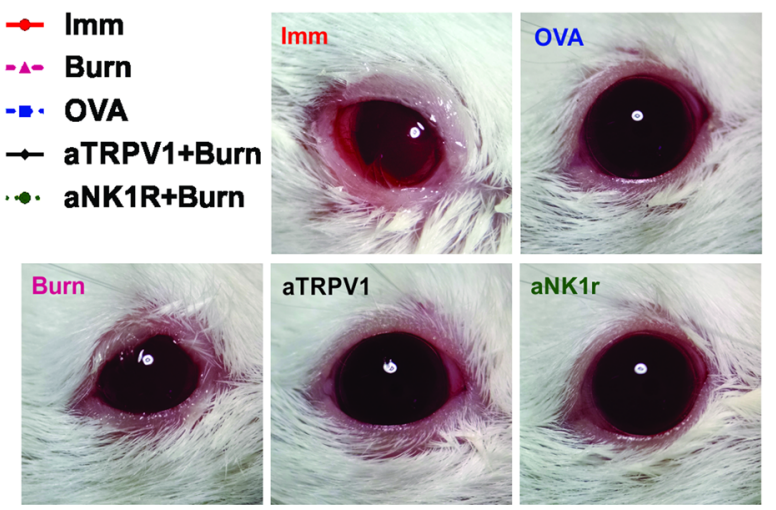

lid edema, tearing, and discharge on a scale from 0 to 3 (overall score 0-9) and averaged. On day 30, blood was collected by terminal cardiac puncture, and serum from each mouse was stored at $-20^{\circ} \mathrm{C}$.

Eye explants and cells from eye-draining lymph nodes

After euthanasia, the entire eye globe with the tarsal conjunctiva still attached was excised with the aid of a dissection microscope, as described elsewhere. ${ }^{12}$ The explants were used for cultured primary epithelial conjunctival cells or fixed with $4 \%$ paraformaldehyde (PFA) for immunostaining. For analysis of eye-draining lymph node cells, submandibular lymph nodes were excised and rendered into a cell suspension by mechanical dissociation and sieving through wire mesh.

\section{Cell lines and cultures}

All cultures were done in RPMI-1640 medium supplemented with $10 \%$ fetal calf serum, $10 \mathrm{mM}$ glutamine, $100 \mathrm{U} / \mathrm{ml}$ penicillin, 100 $\mu \mathrm{g} / \mathrm{ml}$ streptomycin, and $5 \times 10^{-5} \mathrm{M}$ 2-mercaptoethanol in a
Fig. 6 Sympathetic breakdown of mucosal tolerance favors an allergic conjunctival reaction in the opposite ocular surface. a Experimental design for dissecting the inter-eye neurogenic inflammatory reflex contribution to development of ocular allergy. On day 1, a TRPV1 blocker (aTRPV1, SB-366791) was administered repeatedly to the right eye and/or a substance $P$ blocker (aNK1R) was repeatedly applied on the left eye of mice $1 \mathrm{~h}$ before inducing a corneal burn in the right eye. Antigen (OVA) was instilled on the left eye from days 2 to 5 , and then s.c. immunization ( $\mathrm{Imm}$ ) was performed with OVA+alum. Starting on day 21, mice were challenged daily with OVA on both eyes for 10 consecutive days. b Clinical score of ocular allergic response graded $20 \mathrm{~min}$ after challenge every 2 days. Control mice $(\mathrm{Imm})$ only received OVA + alum s.c. before ocular antigen challenge on day 21, whereas OVA mice were tolerized by topical OVA administration to the left eye on days 2-5 before immunization. Burn, aTRPV1+Burn, and aNK1R +Burn mice had a corneal burn induced in the right eye on day 1 and received either saline or said antagonist in the corresponding eye, as detailed in a. Pooled data (mean \pm SD) of 3 experiments with 4-6 mice/group (two-way ANOVA with Dunnett's multiple comparisons test against OVA group). c OVA-specific IgE levels in sera obtained from mice on day 30 of experiment a, as assessed by indirect ELISA. Sera from control mice (gray dots) is included for reference. Pooled data (mean \pm SD) of 3 experiments with 4-6 mice/ group (one-way ANOVA with Dunnett's multiple comparisons test against OVA group). d Representative photographs of mouse eyes obtained 20 min after OVA challenge on day 8 . For all panels, asterisk $(*)$ indicates a statistically significant difference by the corresponding test

humidified incubator with $5 \% \mathrm{CO}_{2}$ at $37^{\circ} \mathrm{C}$. B16 (MO5) melanoma cells were a kind gift from Dr. Cassataro. ${ }^{43} \mathrm{~A}$ conjunctival epithelial cell line (NAV14) was derived by immortalization of a primary epithelial culture of a Balb/c mouse conjunctival explant. After 15 days of culture, cells were transfected with lipofectamine/pSV3neo plasmid in serum-free Opti-MEM medium for $2 \mathrm{~h}$, and then stable transfectants were selected with $1 \mathrm{mg} / \mathrm{ml}$ geneticin for 1 week and cloned by dilution. Epithelial phenotype, monolayer growth, and expression of cytokeratin 13 (conjunctival epithelial marker) and lack of cytokeratin 12 (corneal epithelial marker) were confirmed in the NAV14 clone, which was expanded and cryopreserved.

Immunostaining and flow cytometry

For antigen staining, cells from eye-draining lymph nodes were washed in PBS with $0.5 \%$ bovine serum albumin (BSA), incubated for $15 \mathrm{~min}$ with $5 \mathrm{mg} / \mathrm{ml} 2.4 \mathrm{G} 2$ antibody (purified from ascites fluid) to block non-specific binding to Fc receptors, and then labeled with fluorochrome-conjugated antibodies for $30 \mathrm{~min}$ at $4{ }^{\circ} \mathrm{C}$. For flow cytometric analysis, cells were washed in PBS with $1 \mathrm{mM}$ ethylenediamine tetraacetic acid before acquisition on a Partec CyFlow Space cytometer (Sysmex Partec GmbH, Görlitz, Germany). Data were analyzed with the Flowing Software (Perttu Terho, Centre for Biotechnology, Turku, Finland; www.flowingsoftware. com). Optimal compensation and gain settings, as well as viable cell gating, were determined as described previously. ${ }^{15}$

Total RNA preparation, cDNA synthesis, and qRT-PCR

Total RNA from conjunctiva and eye-draining lymph nodes was extracted using TRIzol reagent, and CDNA was generated by reverse transcription with MMLV RT according to the manufacturer's instructions. qRT-PCR was performed using SYBR Green PCR Master Mix in $20 \mu \mathrm{l}$ reactions. Primers were designed using the Primer3 software, purchased from Ruralex-Fagos (Buenos Aires, Argentina) and used at $250 \mathrm{nM}$ : glyceraldehyde 3-phosphate dehydrogenase (GAPDH) Fw 5' CTCCCACTCTTCCACCTTCG 3', GAPDH Rv 5' CCACCACCCTGTTGCTGTAG 3', IL-1 $\beta$ Fw 5' AAAGCT 


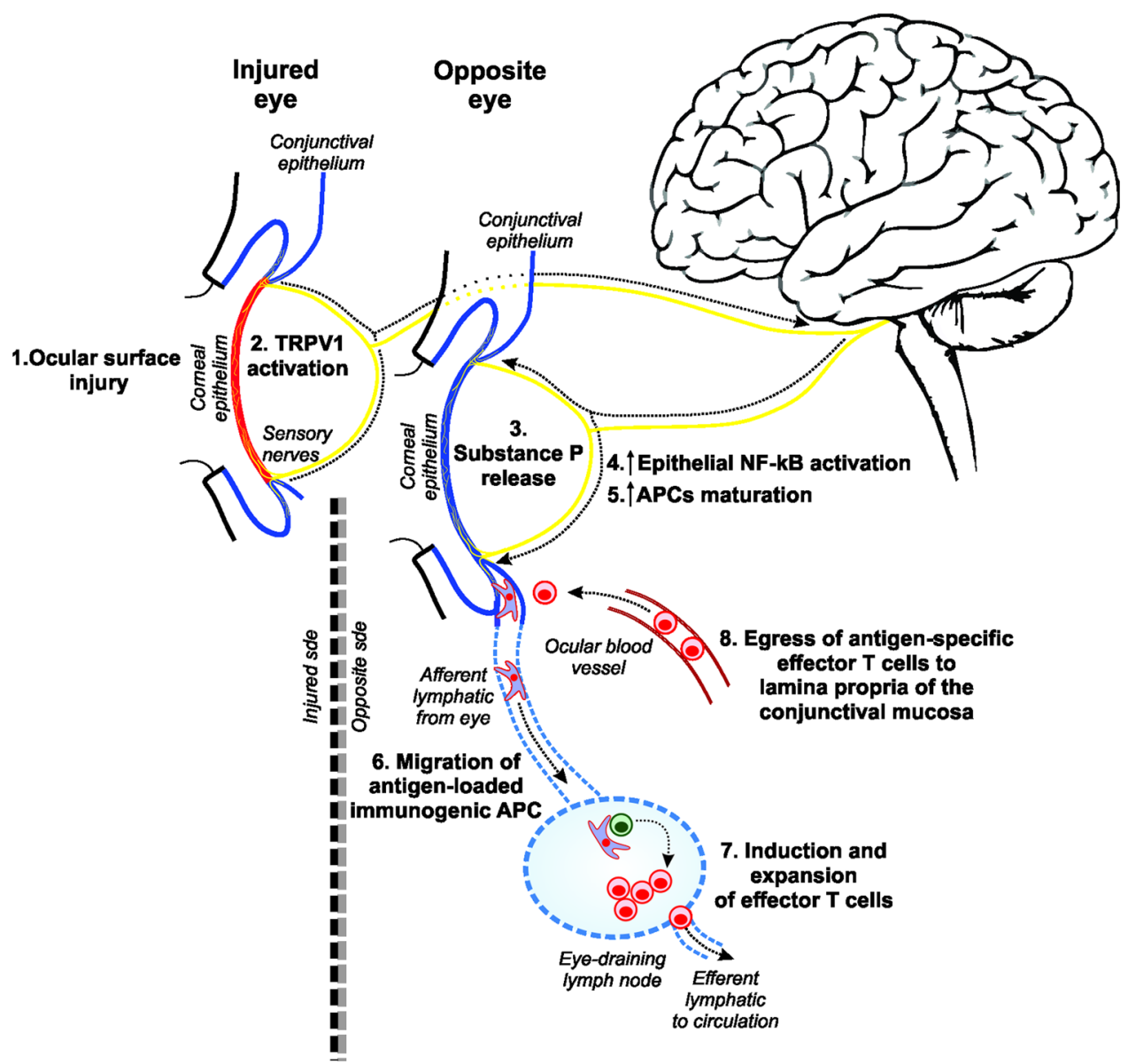

Fig. 7 A neurogenic inflammatory reflex links the ocular mucosal surfaces of both eyes. When the ocular surface of one eye is injured severely enough to damage sensory nerve endings (1), a signal triggered by transient receptor potential vanilloid 1 (TRPV1) channel activation in polymodal nociceptors (2) reaches the central nervous system. Then, from the brain stem, an efferent signal is sent to the opposite eye through the corresponding trigeminal sensory fibers. In response to this efferent signal, substance $P$ is released probably from these same nerve terminals (3) in the opposite ocular surface, where it increases activation of the NF- $\mathrm{KB}$ pathway in conjunctival epithelial cells (4) and it promotes conjunctival antigen-presenting cell (APC) maturation (5). Both events cause the migration of antigen-loaded immunogenic APC (6) to the eye-draining lymph node, where they induce the expansion of effector T cells instead of regulatory $T$ cells (7). These $T$ cells later abandon the lymph node and recirculate, eventually reaching the conjunctival lamina propria (8), where they exert their proinflammatory immune effects upon encountering their cognate antigen

CTCCACCTCAATGG 3', IL-1 $\beta$ Rv 5' AGGCCACAGGTATTITGTCG 3', TNF-a FW $5^{\prime}$ CTTCTCATTCCTGCTTGTGG $3^{\prime}$, TNF-a Rv $5^{\prime}$ GGGAACTTCTCATCCCTTTG $3^{\prime}$, IFN- $\gamma$ FW $5^{\prime}$ GCGTCATTGAATCACACCTG $3^{\prime}$, and IFN- $\gamma$ Rv $5^{\prime}$ TGAGCTCATTGAATGCTTGG $3^{\prime}$. Reactions were carried out in a RotorGene $\mathrm{Q}$ cycler (Qiagen). The cycling program used was $50^{\circ} \mathrm{C}$ for $2 \min , 95^{\circ} \mathrm{C}$ for $2 \mathrm{~min}$, followed by 40 cycles of $95^{\circ} \mathrm{C}$ for $15 \mathrm{~s}, 60^{\circ} \mathrm{C}$ for $60 \mathrm{~s}$. Results were normalized to GAPDH housekeeping gene and represented as relative units $\left(2-\Delta \mathrm{Ct} \times 10^{4}\right)$.

Enzyme-linked immunosorbent assay (ELISA)

IFN- $y$ concentrations in culture supernatants were determined with a commercial ELISA kit according to the manufacturer's instructions (BD Biosciences, Buenos Aires, Argentina). Culture supernatants were collected after overnight stimulation of $1 \times 10^{5}$ lymph node cells on anti-CD3-coated 96-well microplates and assayed in duplicates. OVA-specific IgE levels in serum were determined with an indirect ELISA. In brief, 96-well microtiter plates were coated overnight with $100 \mu \mathrm{g} / \mathrm{ml}$ OVA in PBS, blocked with $5 \%$ BSA for $2 \mathrm{~h}$, incubated with 1:20 and 1:200 serum dilutions for $2 \mathrm{~h}$, then incubated with $5 \mu \mathrm{g} / \mathrm{ml}$ purified anti-mouse lgE biotinylated antibody (cat \# 406904, BioLegend), and finally horseradish peroxidase and chromogenic substrate was added at a previously determined optimal concentration. Reaction was stopped with $1 \mathrm{~N} \mathrm{H}_{2} \mathrm{SO}_{4}$ and absorbance at $405 \mathrm{~nm}$ was measured with a reference filter set at $570 \mathrm{~nm}$.

Immunostaining and confocal laser scanning microscopy acquisition

After fixation with PFA $4 \%$ for $1 \mathrm{~h}$, the whole excised conjunctivas or the cultured conjunctival epithelial cells were sequentially permeabilized with Triton X-100 0,01\% in PBS for $1 \mathrm{~h}$ at room temperature (RT), blocked with BSA $1 \%$ in PBS for $1 \mathrm{~h}$ at RT, incubated with $4 \mu \mathrm{g} / \mathrm{ml}$ anti-NF-KB p65 primary antibody (sc-372; Santa Cruz Biotechnology, CA, USA) in blocking buffer for $2 \mathrm{~h}$ at $4^{\circ}$ $C$, washed, incubated with $2 \mu \mathrm{g} / \mathrm{ml}$ Alexa Fluor 488 goat antirabbit IgG secondary antibody (Jackson ImmunoResearch, PA, USA) for $1 \mathrm{~h}$ at $4{ }^{\circ} \mathrm{C}$, and finally incubated with $1 \mu \mathrm{M}$ ToPro-3 (ThermoFisher Scientific) and $1 \mu \mathrm{g} / \mathrm{ml}$ rhodamine phalloidin for 30 min at $4{ }^{\circ} \mathrm{C}$ for nuclear and actin staining, respectively. Finally, specimens were washed and mounted with AcquaPolymount medium and stored at $4{ }^{\circ} \mathrm{C}$. Image acquisition was performed with a FluoView FV1000 confocal microscope (Olympus, Tokyo, Japan) equipped with a Plapon $60 \times / 1.42$ objective. First, the conjunctival 
epithelial layer was focused by observing ToPro-3 and phalloidin staining only, and then the complete fluorescent images were acquired. Each conjunctiva was cut into 4 pieces before mounting, and at least 20 independent images were obtained from each sample. To ensure objectivity, image acquisition was performed by an experienced technician who was blind to the experimental protocol and without considering the NF-KB p65 label for choosing each field of view. High-resolution images were taken in square regions of $70.66 \mu \mathrm{m}$ per side with a pixel size of $69 \mathrm{~nm}$.

\section{Automated image analysis}

Images were analyzed using the Fiji software with the aid of custom-made macros for automatized quantification. In all cases, values were obtained individually per cell using two regions of interest (ROls). First, each nuclear ROI was determined from a binary image created with the ToPro-3 label. Then free-hand ROls were created by delimiting cell membranes according to phalloidin label. The two first steps were done by a masked observer who was blind to the NF-KB p65 label. Finally, a macro was used to apply both ROls to the NF-KB p65 fluorescent image, and the sum of the total intensity per pixel (RawlntDent) of each area was recorded. Values are expressed as the percentage of nuclear fluorescence in relation to the total fluorescence of each cell analyzed. At least 10 cells per image were analyzed.

Statistical analysis

Student's $t$-test and one- or two-way analysis of variance with Bonferroni or Dunnett's post-hoc tests were used to compare means of two or more samples, respectively. Log-rank (Mantel-Cox) test was used to analyze tumor growth rates. Significance was set at $p<0.05$ and two-tailed tests were used in all experiments. Calculations were performed using the GraphPad Prism version 6 software (GraphPad Software, La Jolla, CA, USA).

\section{ACKNOWLEDGEMENTS}

This work was supported by Agencia Nacional de Promoción Científica y Técnica, Argentina: FONCyT PICT 2013-1436, PICT 2015-0971.

\section{AUTHOR CONTRIBUTIONS}

Study conception and design: M.G., A.S.T., M.N.G., J.G.G.; acquisition of data: M.G., M.S. M., N.R.Z., A.C., M.B.A., I.A.K., F.S., F.F., M.N.G., J.G.G.; analysis and interpretation of data: M.G., M.S.M., A.C., M.B.A., I.A.K., F.F., M.N.G., J.G.G.; drafting of manuscript: M.G., J.G.G.; critical revision: all the authors.

\section{ADDITIONAL INFORMATION}

Competing interests: The authors declare no competing interests.

\section{REFERENCES}

1. Arevalo, J. F., Garcia, R. A., Al-Dhibi, H. A., Sanchez, J. G. \& Suarez-Tata, L. Update on sympathetic ophthalmia. Middle East Afr. J. Ophthalmol. 19, 13-21 (2012).

2. Paunicka, K. J., et al. Severing corneal nerves in one eye induces sympathetic loss of immune privilege and promotes rejection of future corneal allografts placed in either eye. Am. J. Transplant. https://doi.org/10.1111/ajt.13240 (2015).

3. Mo, J., Neelam, S., Mellon, J., Brown, J. R. \& Niederkorn, J. Y. Effect of corneal nerve ablation on immune tolerance induced by corneal allografts, oral immunization, or anterior chamber injection of antigens. Investig. Opthalmol. Vis. Sci. 58, 137 (2017).

4. Lucas, K., Karamichos, D., Mathew, R., Zieske, J. D. \& Stein-Streilein, J. Retinal laser burn-induced neuropathy leads to substance P-dependent loss of ocular immune privilege. J. Immunol. 189, 1237-1242 (2012)

5. Ferrari, G. et al. Ocular surface injury induces inflammation in the brain: in vivo and ex vivo evidence of a corneal-trigeminal axis. Invest. Ophthalmol. Vis. Sci. 55, 6289-6300 (2014)

6. Galletti, J. G., Guzmán, M. \& Giordano, M. N. Mucosal immune tolerance at the ocular surface in health and disease. Immunology 150, 397-407 (2017).
7. Egan, R. M. et al. In vivo behavior of peptide-specific T cells during mucosal tolerance induction: antigen introduced through the mucosa of the conjunctiva elicits prolonged antigen-specific T cell priming followed by anergy. J. Immunol. 164, 4543-4550 (2000).

8. El Rami, H., Fadlallah, A., Fahd, D. \& Fahed, S. Patient-perceived pain during laser in situ keratomileusis: comparison of fellow eyes. J. Cataract Refract. Surg. 38, 453-457 (2012)

9. Ursea, R., Feng, M. T., Zhou, M., Lien, V. \& Loeb, R. Pain perception in sequential cataract surgery: comparison of first and second procedures. J. Cataract Refract. Surg. 37, 1009-1014 (2011).

10. Ferrari, G., Bignami, F., Giacomini, C., Franchini, S. \& Rama, P. Safety and efficacy of topical infliximab in a mouse model of ocular surface scarring. Invest. Ophthalmol. Vis. Sci. 54, 1680-1688 (2013).

11. Zheng, X., de Paiva, C. S., Li, D.-Q., Farley, W. J. \& Pflugfelder, S. C. Desiccating stress promotion of Th17 differentiation by ocular surface tissues through a dendritic cellmediated pathway. Invest. Ophthalmol. Vis. Sci. 51, 3083-3091 (2010).

12. Galletti, J. G. et al. Benzalkonium chloride breaks down conjunctival immunological tolerance in a murine model. Mucosal Immunol. 6, 24-34 (2013).

13. Guzmán, M. et al. Restoring conjunctival tolerance by topical nuclear factor-KB inhibitors reduces preservative-facilitated allergic conjunctivitis in mice. Invest. Ophthalmol. Vis. Sci. 55, 6116-6126 (2014).

14. Guzmán, M. et al. Desiccating stress-induced disruption of ocular surface immune tolerance drives dry eye disease. Clin. Exp. Immunol. 184, 248-256 (2016).

15. Guzmán, M. et al. Mucosal tolerance disruption favors disease progression in an extraorbital lacrimal gland excision model of murine dry eye. Exp. Eye Res. 151, 19-22 (2016).

16. Jankowska-Gan, E., Hegde, S. \& Burlingham, W. J. Trans-vivo delayed type hypersensitivity assay for antigen specific regulation. J. Vis. Exp. e4454 (2013).

17. Overwijk, W. W. \& Restifo, N. P. B16 as a mouse model for human melanoma. Curr. Protoc. Immunol. Chapter 20: Unit 20.1 (2001).

18. Ashley, M. P. \& Kotlarski, I. In vivo cytotoxic responses induced by allogeneic normal and neoplastic cells in mice: relative lack of immunogenicity of B16 melanoma cells. Cell. Immunol. 101, 156-167 (1986).

19. Swamy, M., Jamora, C., Havran, W. \& Hayday, A. Epithelial decision makers: in search of the "epimmunome". Nat. Immunol. 11, 656-665 (2010).

20. Ather, J. L., Foley, K. L., Suratt, B. T., Boyson, J. E. \& Poynter, M. E. Airway epithelial NF-KB activation promotes the ability to overcome inhalational antigen tolerance. Clin. Exp. Allergy 45, 1245-1258 (2015).

21. Baratin, M. et al. Homeostatic NF-kB signaling in steady-state migratory dendritic cells regulates immune homeostasis and tolerance. Immunity 42, 627-639 (2015).

22. Paschalis, E. I. et al. Mechanisms of retinal damage after ocular alkali burns. Am. J. Pathol. 187, 1327-1342 (2017).

23. Tsuji, F. \& Aono, H. Role of transient receptor potential vanilloid 1 in inflammation and autoimmune diseases. Pharmaceuticals (Basel) 5, 837-852 (2012).

24. Nakamura, A. et al. Morphological and immunohistochemical characterization of the trigeminal ganglion neurons innervating the cornea and upper eyelid of the rat. J. Chem. Neuroanat. 34, 95-101 (2007).

25. Chui, J., Di Girolamo, N., Coroneo, M. T. \& Wakefield, D. The role of substance P in the pathogenesis of pterygia. Investig. Opthalmol. Vis. Sci. 48, 4482 (2007).

26. Ozbek, Z. et al. Sympathetic ophthalmia following vitreoretinal surgery. Int. Ophthalmol. 30, 221-227 (2010).

27. Suominen, J. J. Sympathetic auto-immune orchitis. Andrologia 27, 213-216 (1995).

28. Naito, M. et al. Experimental autoimmune orchitis as a model of immunological male infertility. Med. Mol. Morphol. 45, 185-189 (2012).

29. Koltzenburg, M., Wall, P. D. \& McMahon, S. B. Does the right side know what the left is doing? Trends Neurosci. 22, 122-127 (1999).

30. Shenker, N. et al. A review of contralateral responses to a unilateral inflammatory lesion. Rheumatology 42, 1279-1286 (2003).

31. Belmonte, C., Acosta, M. C., Merayo-Lloves, J. \& Gallar, J. What causes eye pain? Curr. Ophthalmol. Rep. 3, 111-121 (2015).

32. Murata, Y. \& Masuko, S. Peripheral and central distribution of TRPV1, substance $P$ and CGRP of rat corneal neurons. Brain Res. 1085, 87-94 (2006).

33. Rivera, L., Gallar, J., Pozo, M. A. \& Belmonte, C. Responses of nerve fibres of the rat saphenous nerve neuroma to mechanical and chemical stimulation: an in vitro study. J. Physiol. 527(Pt 2), 305-313 (2000).

34. Park, Y., Hwang, H. B. \& Kim, H. S. Observation of influence of cataract surgery on the ocular surface. PLOS ONE 11, e0152460 (2016).

35. Taylor, A. W. Ocular immune privilege and transplantation. Front. Immunol. 7, 37 (2016).

36. Corrigan, F., Mander, K. A., Leonard, A. V. \& Vink, R. Neurogenic inflammation after traumatic brain injury and its potentiation of classical inflammation. J. Neuroinflamm. 13, 264 (2016).

37. Suvas, S. Role of substance $P$ neuropeptide in inflammation, wound healing, and tissue homeostasis. J. Immunol. 199, 1543-1552 (2017). 
The mucosal surfaces of both eyes are immunologically...

M Guzmán et al.

38. Janelsins, B. M. et al. Proinflammatory tachykinins that signal through the neurokinin 1 receptor promote survival of dendritic cells and potent cellular immunity. Blood 113, 3017-3026 (2009).

39. Gaddipati, S. et al. Loss of neurokinin-1 receptor alters ocular surface homeostasis and promotes an early development of herpes stromal keratitis. J. Immunol. 197, 4021-4033 (2016).

40. Barbosa, F. L. et al. Goblet cells contribute to ocular surface immune toleranceimplications for dry eye disease. Int. J. Mol. Sci. 18, 978 (2017).
41. Cruzat, A. et al. Contralateral clinically unaffected eyes of patients with unilateral infectious keratitis demonstrate a sympathetic immune response. Invest. Ophthalmol. Vis. Sci. 56, 6612-6620 (2015).

42. Bai, J.-Q., Qin, H.-F. \& Zhao, S.-H. Research on mouse model of grade II corneal alkali burn. Int. J. Ophthalmol. 9, 487-490 (2016).

43. Coria, L. M. et al. A Brucella spp. protease inhibitor limits antigen lysosomal proteolysis, increases cross-presentation, and enhances CD8+T cell responses. J. Immunol. 196, 4014-4029 (2016). 